\title{
CYP46A1 Activation by Efavirenz Leads to Behavioral Improvement without Significant Changes in Amyloid Plaque Load in the Brain of 5XFAD Mice
}

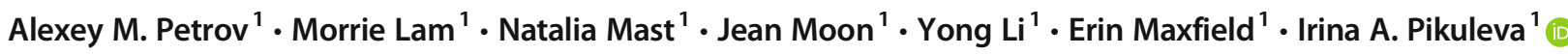 \\ Published online: 6 May 2019 \\ (C) The American Society for Experimental NeuroTherapeutics, Inc. 2019
}

\begin{abstract}
Efavirenz, the FDA-approved anti-retroviral medication, is evaluated in the clinical trial in patients with mild cognitive impairment or early dementia due to Alzheimer's disease. Efavirenz is assessed for activation of cytochrome P450 46A1 (CYP46A1), a CNS-specific enzyme that converts cholesterol to 24-hydroxycholesterol. Cholesterol 24-hydroxylation is the major pathway for brain cholesterol removal, and a mechanism that controls brain cholesterol turnover. The present study tested efavirenz on 5XFAD mice (an Alzheimer's model) at a very low daily dose of $0.1 \mathrm{mg} / \mathrm{kg}$ body weight. Efavirenz treatment started from three months of age, after amyloid plague appearance, and continued for 6 months. This treatment led to CYP46A1 activation in the brain, enhancement of brain cholesterol turnover, behavioral improvements, reduction in microglia activation but increased astrocyte reactivity. The levels of the soluble and insoluble amyloid 40 and 42 peptides were unchanged while the number and area of the dense core amyloid plaques were slightly decreased. The measurements of the brain levels of several pre- and post-synaptic proteins (Munc13-1, PSD-95, gephyrin, synaptophysin, synapsin-1, and calbindin-D28k) suggested efavirenz effect at the synaptic level. Efavirenz treatment in the present work seems to represent a model of behavioral and other improvements independent of the levels of the amyloid peptides and provides insight into potential outcomes of the future clinical trial.
\end{abstract}

Key Words CYP46A1 $\cdot$ Efavirenz $\cdot$ Alzheimer's disease $\cdot 24$-hydroxycholesterol $\cdot$ Astrocytes $\cdot$ Microglia $\cdot$ Synaptic proteins

$\begin{array}{ll}\text { Abbreviations } \\ \text { A } \beta & \text { Amyloid } \beta \text { Peptide } \\ \text { AD } & \text { Alzheimer's Disease } \\ \text { APP } & \text { Amyloid Precursor Protein } \\ \text { CS } & \text { Conditioned Stimulus } \\ \text { CYP46A1 } & \text { Cytochrome P450 46A1 } \\ \text { EFV } & \text { Efavirenz } \\ \text { GABA } & \text { Gamma-Aminobutyric Acid } \\ \text { GFAP } & \text { Glial Fibrillary Acidic Protein } \\ \text { 24HC } & \text { 24-Hydroxycholesterol } \\ \text { HMGCR } & \text { 3-Hydroxy-3-Methylglutaryl-CoA Reductase } \\ \text { Iba1 } & \text { Ionized Calcium Binding Adaptor Molecule 1 } \\ \text { LXR } & \text { Liver X Receptor } \\ \text { MWM } & \text { Morris Water Maze }\end{array}$

Irina A. Pikuleva

iap8@case.edu

1 Department of Ophthalmology and Visual Sciences, Case Western Reserve University, 2085 Adelbert Rd., Room 303, Cleveland, OH 44106, USA
NMDAR N-Methyl-D-Aspartate Receptors

PBS Phosphate Buffer Saline

US Unconditioned Stimulus

Currently, there are no disease-modifying treatments for Alzheimers' disease (AD); all therapies are symptomatic and include inhibitors of cholinesterase as well as memantine, a partial antagonist of $\mathrm{N}$-methyl-D-aspartate receptors (NMDAR) and agonist of dopamine D2 receptors [1]. Different targets and pathways are now evaluated for development of disease-modifying therapies for AD. Among them are studies of cytochrome P450 46A1 (CYP46A1), normally a neuron-specific enzyme responsible for the conversion of cholesterol to 24-hydroxycholesterol (24HC) [2-4]. Unlike cholesterol, which cannot cross the blood-brain barrier, 24HC rapidly diffuses out of the brain into systemic circulation and is delivered to the liver for further degradation to bile acids [2, 5]. In the brain, cholesterol is mainly present in the membranes of compact myelin, which in mice contain $\sim 78 \%$ of the total pool of brain cholesterol. The remaining cholesterol 
$(\sim 22 \%)$ is found in other plasma membranes including those of neurons, which could have $\sim 2.2 \%$ of total brain cholesterol [6]. Cholesterol 24-hydroxylation is the major mechanism for cholesterol elimination from the brain; in addition, this enzymatic reaction controls brain cholesterol biosynthesis and turnover [2, 7]. Indeed, most of brain cholesterol is thought to be synthesized by astrocytes and delivered to neurons, where its excess is removed by metabolism to $24 \mathrm{HC}$ [8]. Accordingly, decreasing or increasing cholesterol metabolism to $24 \mathrm{HC}$ leads to a compensatory down- or upregulation of cholesterol biosynthesis to keep the cholesterol levels unchanged; in addition this response alters the rate of brain cholesterol turnover $[7,9,10]$. Besides the metabolic role, CYP46A1 may be of a regulatory importance via the production of 24HC. Recently, 24HC was discovered to be a positive allosteric modulator of NMDAR involved in memory and cognition [11, 12]. 24HC is also a potent activator of liver $\mathrm{X}$ receptors (LXRs), transcription factors that regulate sterol, fatty acid, triglyceride, and glucose metabolism along with immune and inflammatory responses in a tissue-specific manner [13-15]. Studies show that LXR activation can promote synaptic plasticity and increase neurogenesis $[16,17]$.

There are several associations between CYP46A1 and AD. First, plasma levels of $24 \mathrm{HC}$ are altered in AD: $24 \mathrm{HC}$ is slightly increased during the early disease stage and decreased with disease progression [18-20]. Second, AD also affects CYP46A1 distribution in the brain; the disease induces CYP6A1 expression in reactive glial fibrillary acidic protein (GFAP)-positive) astrocytes [21-23]. Third, some but not all linkage studies established the association of polymorphisms in CYP46Al (could be as frequent as 40\%) with $\mathrm{AD}$ [24]. Finally, in different mouse models of AD, increasing the expression of CYP46A1 by genetic means or enhancing CYP46A1 activity pharmacologically was found to improve animal performance in behavioral tests and decrease amyloid $\beta(A \beta)$ or tau pathology [10, 25-27]. In contrast, silencing Cyp46a1 expression in the hippocampus of adult mice led to AD-like pathology and was accompanied by a production of $A \beta$ peptides along with tau hyperphosphorylation [28, 29]. Yet, in a mouse model of AD, Cyp $46 a 1$ ablation did not markedly affect the rates and extent of amyloid plaque formation but increased longevity [30].

Previously we discovered that the anti-HIV drug efavirenz (EFV) interacts with CYP46A1 in vitro and in vivo and allosterically activates the P450 at low concentrations/doses, while inhibiting the enzyme at high concentrations/doses by binding to the P450 active site $[9,31]$. Then, we chose 5XFAD mice, a model of rapid amyloidogenesis, and started EFV administration with an activating drug dose of $0.1 \mathrm{mg} / \mathrm{kg}$ body weight immediately after mouse weaning at 1 month of age [10]. The treatment continued for 8 months (we called the study 1 st treatment paradigm), and animals were evaluated at 5 and 9 months of age, i.e., after 4 and 8 months of treatment, respectively. At both time points, EFV administration reduced the levels of $A \beta 42$ peptide. In addition, the 8-month treatment improved animal performance in the Morris Water Maze (MWM) test and reduced the levels of $\mathrm{A} \beta 40$ peptide [10]. Herein, we repeated EFV treatment but started drug administration at 3 months of age, when amyloid plagues were already present in mouse brain [32]. We also shorten the treatment time to 6 months and called the study 2 nd treatment paradigm. We conducted additional experiments to gain insights into the mechanisms of beneficial EFV effects. The data obtained point to changes in the CYP46A1 expression and distribution, changes in the levels of synaptic proteins, differential effects on astrocyte and microglia activation but unchanged $A \beta$ levels. We obtained a better understanding of potential outcomes of our clinical trial (ClinicalTrials.gov, NCT03706885). In addition, we generated a model for studies of the $A \beta$ level-independent mechanisms for behavioral improvement in transgenic mice, which could be of value for understanding the known poor correlation between $A \beta$ accumulation and the extent of cognitive impairments in $\mathrm{AD}$ patients $[33,34]$.

\section{Materials and Methods}

\section{Animals}

5XFAD mice on B6SJL background were obtained by crossing 5XFAD hemizygous males with wild type B6SJL females (stock No: 34840-JAX and 100,012, respectively, The Jackson Laboratory, Bar Harbor, ME). Only F1 generation of the 5XFAD hemizygotes for the transgenes was used. Gender-matched B6SJL littermates served as a control. The $P d e 6 b^{r d l}$ mutation leading to retinal degeneration was bred out of our colony. Mice were maintained in a temperature and humidity-controlled environment with $12 \mathrm{~h}$ light/12 h dark cycle in cages with water and food ad libitum. All animal experiments were approved by the Case Western Reserve University's Institutional Animal Care and Use Committee and conformed to recommendations of the American Veterinary Association Panel on Euthanasia.

\section{EFV Treatment}

The administration of the S-isomer of EFV (Toronto Research Chemicals Inc., North York, Canada) was in drinking water as described [9]. Briefly, EVF was added from a $200 \mathrm{mg} / \mathrm{l}$ aqueous stock containing $0.2 \%(\mathrm{v} / \mathrm{v})$ Tween 80 , and its final concentration in drinking water was $0.42 \mathrm{mg} / \mathrm{l}$. Mice drank approximately $6.0-6.5 \mathrm{ml} /$ day of EFV-containing water from light-protected bottles, a water amount which equals to about $0.1 \mathrm{mg}$ of EFV/day $/ \mathrm{kg}$ of body weight for a $25-\mathrm{g}$ mouse. The treatment started when animals were 3 -month old and 
continued for 6 months. Control mice, which were littermates of EFV-treated mice, received vehicle.

\section{Behavioral Tests}

5XFAD mice were tested individually as follows: Y-maze at day 1; MWM at days 2-6; and fear memory tests at days 14 and 15 after the break at days 7-13. These tests were carried out as described [10]. Briefly, mice were placed in the center of a Y-shaped maze, which consisted of 3 equal arms with a $35 \mathrm{~cm}$ arm length, $6 \mathrm{~cm}$ arm width, and $10 \mathrm{~cm}$ arm height. Animals stayed in the Y-maze for 5-12 min until made 20 arm choices. The alternation rate was then calculated as a degree of arm entries without repetitions. The MWM test was conducted in a black round swimming pool with a diameter of $120 \mathrm{~cm}$. Mice had to find a hidden platform in the pool and were given three trials per day during five consecutive days; swim time and distance were recorded by an automated tracking system (ANY-maze, Stoelting Co., Wood Dale, IL). Latencies (time from start to platform) at each trial were then pooled into one day-block of three trials. For the fear memory tests, mice were placed into a conditioning box (Med Associates Inc., St. Albans, VT) and trained to associate the auditory conditioned stimulus (CS; a pure tone of $3 \mathrm{kHz}, 80 \mathrm{~dB}$ for $30 \mathrm{~s}$ ) with coterminated aversive unconditioned stimulus (US; a footshock of $0.5 \mathrm{~mA}$ for $1 \mathrm{~s})$. This procedure was repeated four times with 120-s accumulation and 60-s inter-stimulus-interval (fear conditioning). Context-dependent fear memory was tested $24 \mathrm{~h}$ later, when mice were placed into the same chamber, and their freezing behavior was counted during $5 \mathrm{~min}$ in the absence of CS. Two hours after contextual fear conditioning, mice were introduced into the chamber with a different odor, shape, lighting, and their freezing behavior was measured (cued fear conditioning) during the first 3 min without CS (non-CS) and then during the second 3 min with CS.

\section{Brain Processing}

Mice were fasted overnight and the next morning terminated. If used for histo- and immunohistochemistry stains, mice were anesthetized and perfused through the heart with phosphate buffer saline (PBS, $30 \mathrm{ml}, 1 \mathrm{ml} / \mathrm{min}$ ) followed by a perfusion with $4 \%$ paraformaldehyde in PBS $(30 \mathrm{ml}, 1 \mathrm{ml} / \mathrm{min})$. The brains were isolated, fixed for 4 days at room temperature in $4 \%$ paraformaldehyde in PBS, and placed into $1 \%$ paraformaldehyde in PBS for storage at $4{ }^{\circ} \mathrm{C}$. If used for Western blots, sterol quantifications, and ELISA, mice were terminated by cervical dislocation and their brains were isolated. Brains were rinsed in cold PBS, blotted, and dissected along the midline. One hemisphere was used for homogenization $(10 \%, w / v)$ in $20 \mathrm{mM}$ Tris- $\mathrm{HCl}, \mathrm{pH} 7.4$, containing $250 \mathrm{mM}$ sucrose, $0.5 \mathrm{mM}$ EDTA, $0.5 \mathrm{mM}$ EGTA, and a cocktail of protease inhibitors (Complete, Roche, Basel, Switzerland).
Tissue homogenate was then subjected to centrifugation at $1500 \mathrm{~g}$ for $15 \mathrm{~min}$. The supernatant obtained was used either for Western blots as described below or sterol quantifications by isotope dilution gas chromatography-mass spectrometry following sample saponification [35]. Another hemisphere was used for $A \beta$ peptide measurements by ELISA as described below after the removal of the cerebellum and brainstem.

\section{Western Blots}

Proteins were separated by SDS-PAGE $(10-20 \mu \mathrm{g}$ protein per lane, $10 \%, 12 \%$ or $4-20 \%$ Tris/Glycine gels, Bio-Rad, Hercules, CA) and transferred to a nitrocellulose membrane (P/N 926-31,092, Li-Cor Biosciences, Lincoln, NE). Subsequent membrane processing was as described [36] and included incubations in the Odyssey blocking buffer (1.5-3 h at room temperature, \#927-40,000, Li-Cor Biosciences, Lincoln, NE) and solutions of primary (overnight at $4{ }^{\circ} \mathrm{C}$ ) and secondary antibodies ( $1 \mathrm{~h}$ at room temperature) in the Odyssey blocking buffer; $0.1 \%$ Tween-20 was added to all of the solutions. The primary and secondary antibodies are described in Table 1. Membranes were imaged by an Odyssey infrared imaging system (Li-Cor Biosciences, Lincoln, NE).

\section{Elisa}

Brain homogenates were prepared as described [37]. Soluble and insoluble $A \beta 40$ and $A \beta 42$ peptides were extracted with $0.2 \%$ diethylamine and $70 \%$ formic acid, respectively [10], and quantified by a sandwich ELISA kit (KHB3482, Invitrogen, Carlsbad, CA) according to the manufacturer's instructions.

\section{Histo- and Immunohistochemistry}

These analyses were as described [10]. Briefly, the brains were cryopreserved, cut sagittally ( $10 \mu \mathrm{m}$-thick, $1.2-1.5 \mathrm{~mm}$ from the midline) and placed on slides. Thioflavin $\mathrm{S}$ stains were with $1 \%$ aqueous solution (Sigma-Aldrich, St. Louis, MO); immunolocalizations were with primary and secondary antibodies described in Table 1. Slides were mounted either with ProLong Gold Antifade reagent with DAPI (P36935, Thermo Fisher Scientific, Waltham, MA) or with VECTASHIELD Antifade Medium with Propidium Iodide (H-1300-10; Vector Laboratories, Inc., Burlingame, CA). Images were acquired on an inverted microscope DMI 6000 B (Leica Microsystems Inc., Buffalo Grove, IL) equipped with a Retiga EXi-Fast camera (QImaging, Surrey, Canada) and analyzed with Metamorph Imaging Software (Molecular Devices, San Jose, CA) as described [10]. A Leica TCS SP8 Confocal microscope (Leica Microsystems Inc., Buffalo 


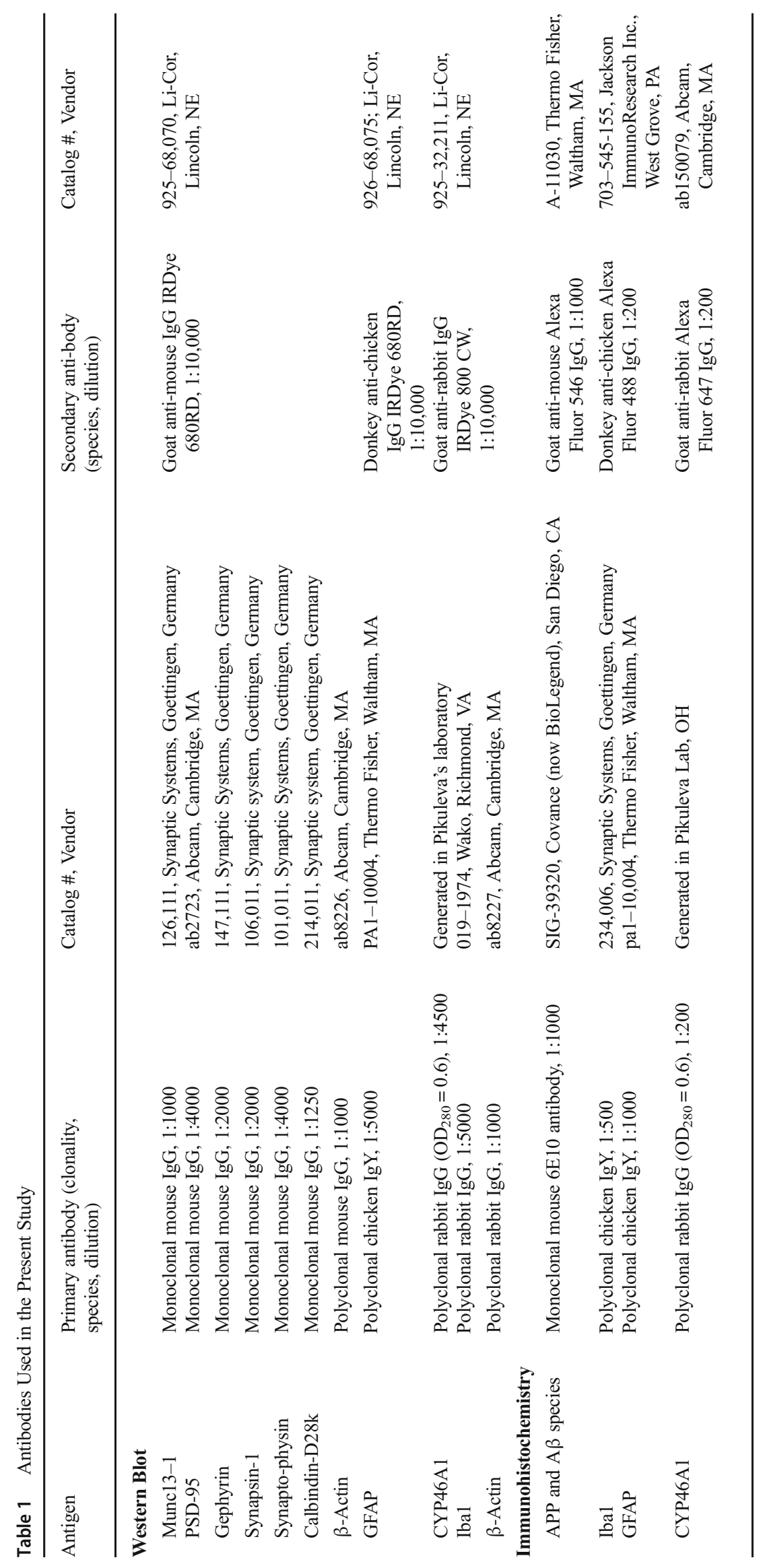


Grove, IL) was used for imaging of sections with doublelabeling against GFAP and CYP46A1.

\section{Statistical Analysis}

All data represent mean $\pm \mathrm{SD}$, except behavioral tests, where the error bars are SEM. Either unpaired Student's $t$ test assuming a two-tailed distribution or repeated measures two-way ANOVA followed by a post hoc Bonferroni multiple comparison test were used. Results were considered statistically significant when $P$ values were $\leq 0.05$. $* P \leq 0.05, * * P \leq 0.01$, $* * * P \leq 0.001$. All histo- and immunohistochemistry images and Western blots are representative of observations in 3-8 mice per group. Each Western blot was repeated two to four times.

\section{Results}

\section{Behavioral Tests}

In the Y-maze test, an indicator of the spatial short-term working memory, the spontaneous alteration rate was not changed in EFV-treated versus control mice (Fig. 1a). Yet, in MWM test, which assesses the spatial long-term memory and learning, EFV-treated group displayed a better performance than the control group (Fig. 1b). In fear conditioning tests, EFVtreated mice exhibited a greater postshock freezing (an index of fear memory) during the learning phase of the contextual fear test (Fig. 1c) and also the next day when the actual test was performed (Fig. 1d). However, in the cued fear conditioning, there was no difference between EFV-treated and control mice (Fig. 1e). Thus, EFV treatment improved the spatial long-term memory as well as the short and long-term contextual fear memory but not the spatial short-term working memory or fear cued memory.

\section{Brain Sterol Profiles}

Four sterols were evaluated in 5XFAD mice after animals were terminated at the end of the 6-month treatment either with EFV or vehicle (Fig. 2). These were cholesterol, lathosterol and desmosterol (the markers of cholesterol biosynthesis in neurons and astrocytes, respectively [8]) as well as $24 \mathrm{HC}$ (the CYP46A1 product). EFV administration did not alter cholesterol and desmosterol levels but increased lathosterol levels by $11 \%$ and $24 \mathrm{HC}$ cholesterol levels by $16 \%$. Thus, CYP46A1 activation by EFV appeared to lead to a compensatory increase in neuronal cholesterol biosynthesis to prevent the brain from cholesterol depletion. This response also increased the brain cholesterol turnover.

\section{Amyloid Pathology}

EFV-treatment did not significantly affect the content of soluble and insoluble $A \beta 40$ and $A \beta 42$ peptides in the whole brain homogenates (Fig. 3a). Similarly, both cortex and hippocampus did not seem to have a decrease in the number and area of staining with 6E10 (Fig. 3b,c), which recognizes amyloid precursor protein (APP) and all $A \beta$ species. Yet, both
Fig. 1 EFV effects on behavioral performance of 5XFAD mice. (a), Y-maze, (b), MWM, and (c-e) fear conditioning tests. The results are presented as means \pm SEM of measurements in individual mice. $* P \leq 0.05$ by a two-way ANOVA with treatment group and trial factors, followed by Bonferroni corrections as a post hoc comparison $(\mathbf{b}, \mathbf{c})$ or an unpaired twotailed Student's t test (d). Cntr, control (vehicle-treated) mice (7 female and 7 male animals); Tx, EFV-treated mice $(9$ female and 8 male animals); US, unconditioned stimulus; and CS, conditioned stimulus

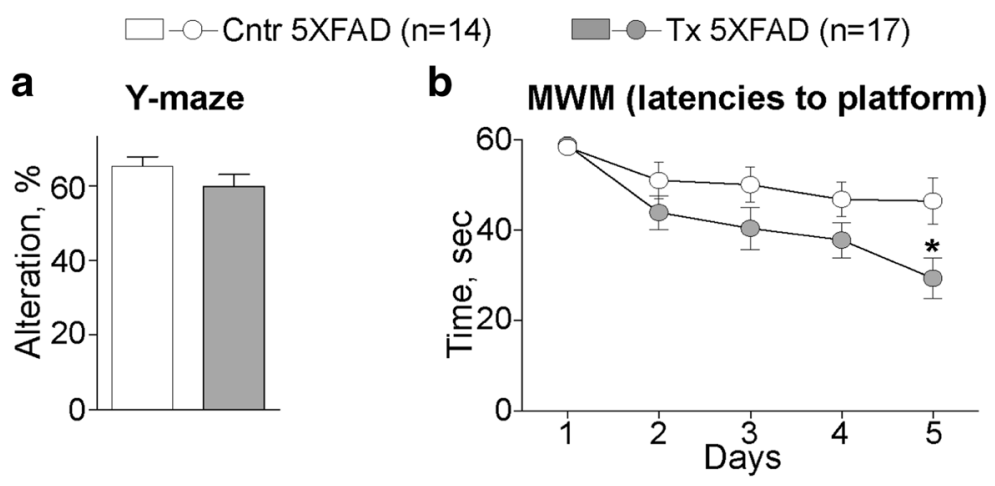

Fear Conditioning
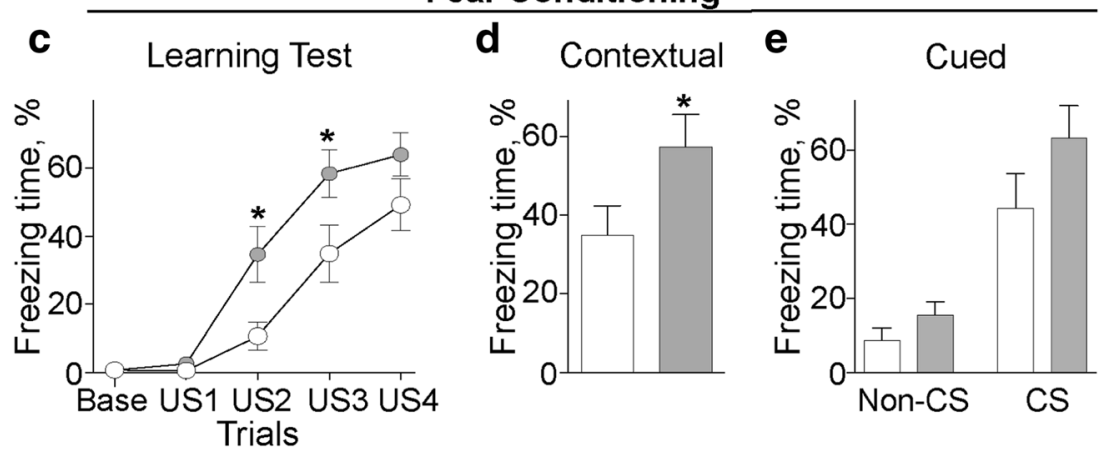
Fig. 2 EFV effects on brain sterol levels in 5XFAD mice. The results are presented as means \pm $\mathrm{SD}$ of measurements in individual mice. $* * P \leq 0.01, * * * P \leq 0.001$ by an unpaired two-tailed Student's t test. Cntr, control mice (6 male animals); Tx, EFV-treated mice (8 male animals)

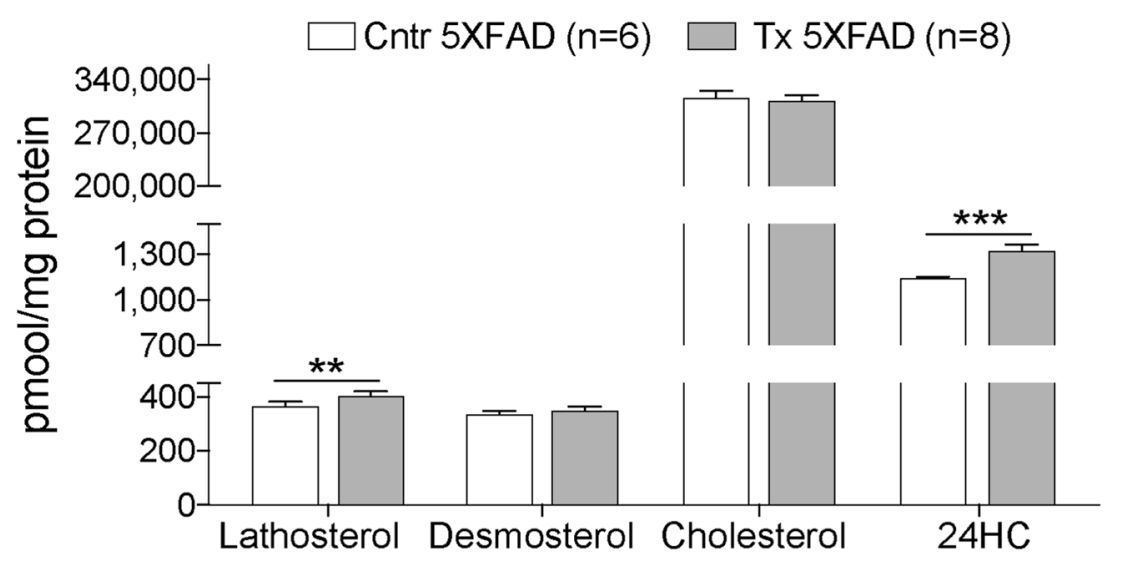

cortex and hippocampus had small but statistically significant decreases in the number (19\% and $18 \%$, respectively) and area (17\% and $20 \%$, respectively) of stainings with Thioflavin S (Fig. 3d,e), which binds to dense core amyloid plaques [38]. Thus, starting EFV treatment after amyloid deposition did not have a pronounced effect on the $A \beta$ levels and only decreased up to $20 \%$ the load of the dense core amyloid plaques in the cortex and hippocampus.

\section{Brain co-Localizations and Levels of CYP46A1, GFAP, and lonized Calcium Binding Adaptor Molecule 1 (lba1)}

CYP46A1 is normally expressed in certain neuronal populations, namely pyramidal neurons of the hippocampus and cortex, Purkinje cells of the cerebellum, and hippocampal and cerebellar interneurons [4]. However, under several pathologic conditions, CYP46A1 was detected in astrocytes and microglia [21, 23, 39]. Hence, two brain regions (the cortex and hippocampus) were analyzed, and brain sections were double stained for CYP46A1 and GFAP or Iba1, markers for reactive astrocytes and activated microglia, respectively [40, 41]. Signals for GFAP and Ibal were weak in Cyp46a1 $1^{-/-}$mice, which served as a negative control for CYP46A1 labeling. In contrast, both control and EFV-treated 5XFAD mice had strong antiGFAP and anti-Ibal signals in agreement with previous findings in 5XFAD mice [32, 42]. In 5XFAD mice, CYP46A1 was co-localized with some but not all GFAP-positive, star-shaped astrocytic cells (Fig. 4a) but there was no detectable CYP46A1 expression in Iba1postive, amoeboid-looking microglial cells (Fig. 4b, data for the hippocampus are not shown because no regions were found where CYP46A1 expression was abundant and comparable with that of Iba1). Also, there seemed to be different signal intensity for GFAP and Iba1 in EFV-treated vs control 5XFAD mice (Fig. 4). Therefore, additional brain regions were analyzed and compared to those in B6SJL mice (Fig. 5). The anti-GFAP and anti-
Iba1 signals were much stronger in the cortex and hippocampus of control 5XFAD mice than B6SJL mice and also different as compared EFV-treated mice. The latter was confirmed by Western blots on the whole brain homogenates, which revealed increased levels of GFAP (by $53 \%$, Fig. 6a,d) and decreased levels of Iba1 (by $40 \%$, Fig. 6) in EFV-treated vs control 5XFAD mice. In addition, EFV treatment decreased the levels of CYP46A1 (by $22 \%$, Fig. 6c,d). Thus, 5XFAD mice have activated astrocytes and microglia with CYP46A1 expression in some of the reactive astrocytes. EFV treatment further increased astrocyte reactivity but reduced microglia activation and the levels of CYP46A1.

\section{Brain Levels of Synaptic Proteins}

Increased CYP46A1 expression and activity in CYP46A1 transgenic mice was found to improve memory function and increase hippocampal levels of several synaptic proteins [43]. Some of these as well as other proteins were quantified in EFV-treated 5XFAD mice (Fig. 7a), i.e., animals which have memory improvements but represent a disease model with CYP46A1 activity enhanced pharmacologically. The levels of six proteins were measured by Western blot in the whole brain homogenates (Fig. 7b-h). Of them, three proteins (PSD-95, synaptophysin, and synapsin-1) were previously measured in the hippocampus of CYP46A1 transgenic mice [43]. EFV treatment led to statistically significant increases in abundance of two proteins essential for glutamatergic transmission: Munc13-1 (by $40 \%$ ), which is associated with presynaptic membranes [44, 45], and PSD-95 (by 30\%), which interacts with postsynaptic membranes [46]. The abundance of gephyrin, a scaffold protein for inhibitory neurotransmitter receptors [47], synaptophysin, a synaptic vesicle protein [48], and calbindin-D28k, a ubiquitous neuronal $\mathrm{Ca}^{2+}$ buffering protein $[49,50]$, remained unchanged, whereas that of synapsin-1, responsible for restraining synaptic vesicles into the reserve pool (in excitatory synapses) or the 


\section{a}

口Female mice

口Male mice

A340 peptide

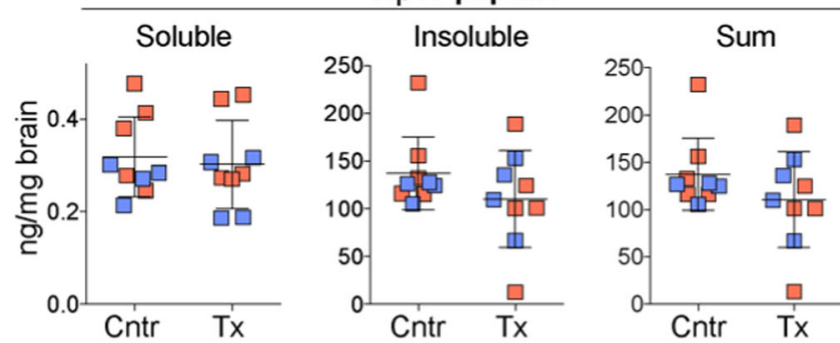

A 342 peptide
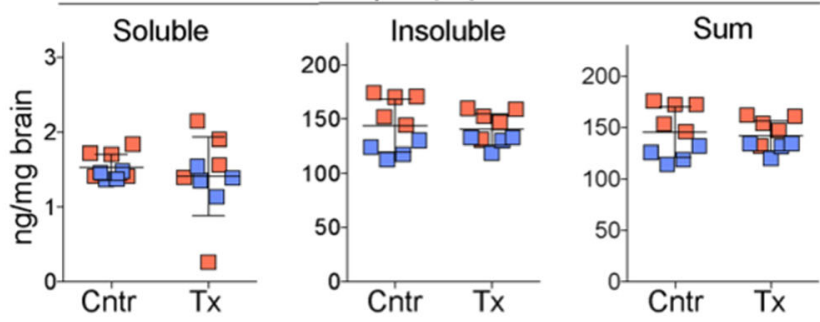

b
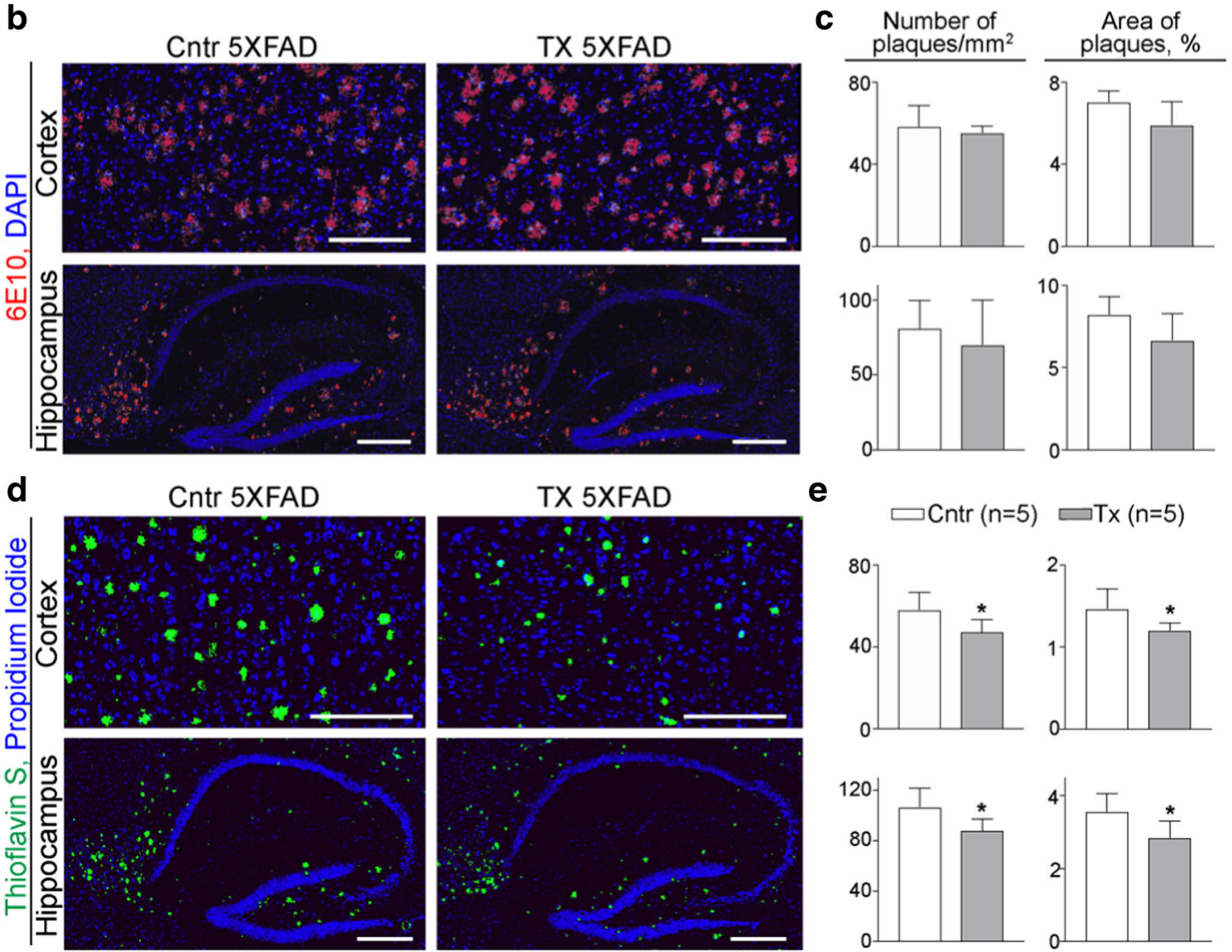

e

$$
\square \operatorname{Cntr}(\mathrm{n}=5) \quad \square \mathrm{Tx}(\mathrm{n}=5)
$$
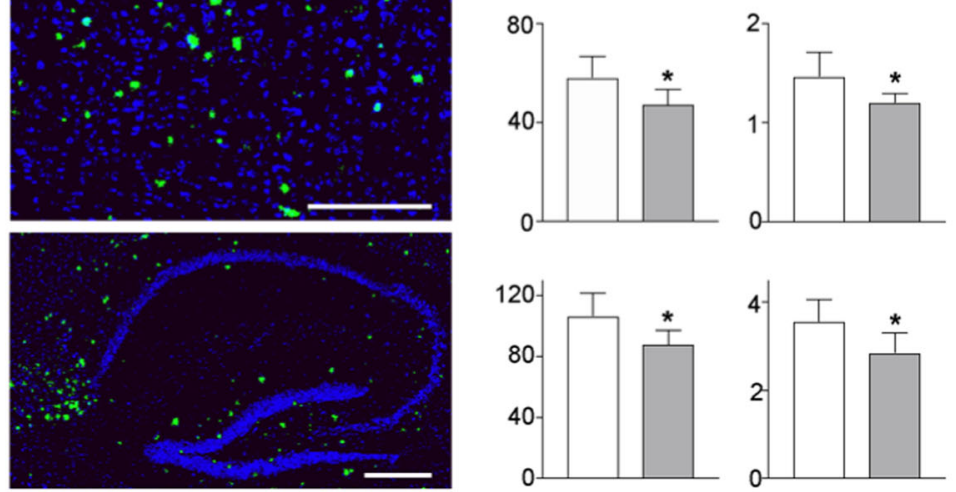

Fig. 3 EFV effects on amyloid pathology. (a) The content of soluble and insoluble amyloid $\beta(\mathrm{A} \beta)$ peptides in the brain homogenates of 5XFAD mice. The quantifications were carried out by ELISA. The results are presented as means \pm SD of measurements in individual mice. Both female ( $n=5$ per treatment group, pink rectangles) and male $(n=4$ per treatment group, blue rectangles) mice were used. No significant differences were found between control (Cntr) and EFV-treated (Tx) mice when female and male mice were analyzed as one group or separately. (b and d) Representative images ( $n=5$ male mice per treatment group) of the brain sections stained with $6 \mathrm{E} 10$ and Thioflavin $\mathrm{S}$, respectively. Nuclei were stained with DAPI (b) or propidium iodide (d, false colored in blue). (c and e) Quantifications of the 6E10- and Thioflavin S-positive plagues. Area of the plaques is expressed as a percentage from the total area of either cortex or hippocampus. $* P \leq 0.05$ by an unpainted, twotailed Student's t test. Cntr, control mice; Tx, EFV-treated mice. Scale bars, $150 \mu \mathrm{m}$ 

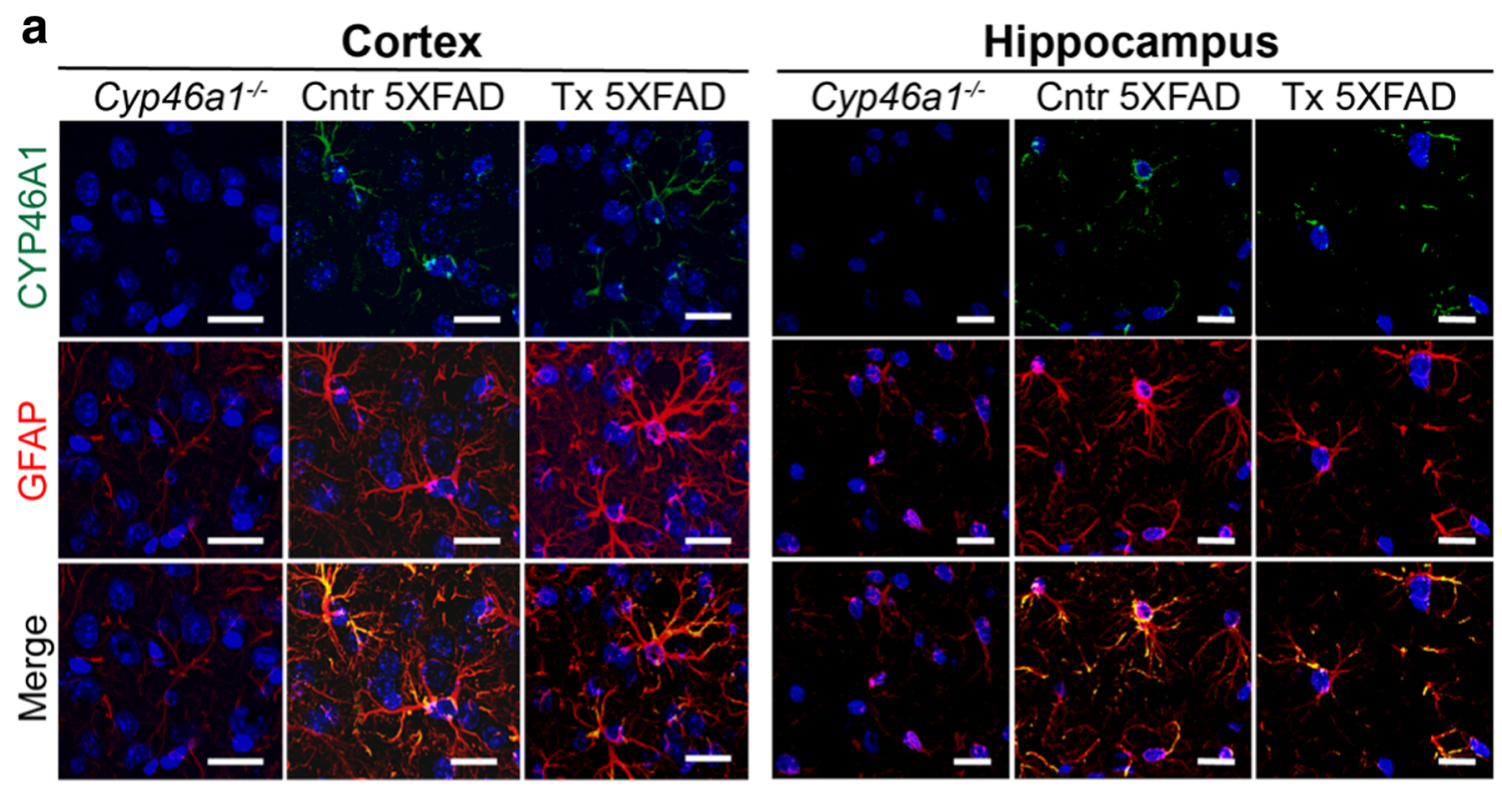

b

Cortex

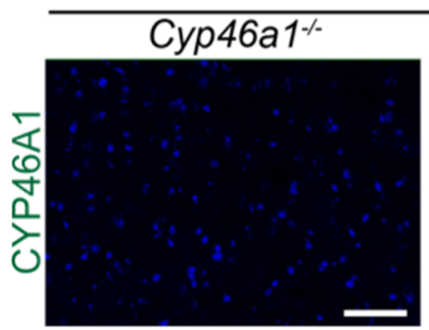

Cntr 5XFAD
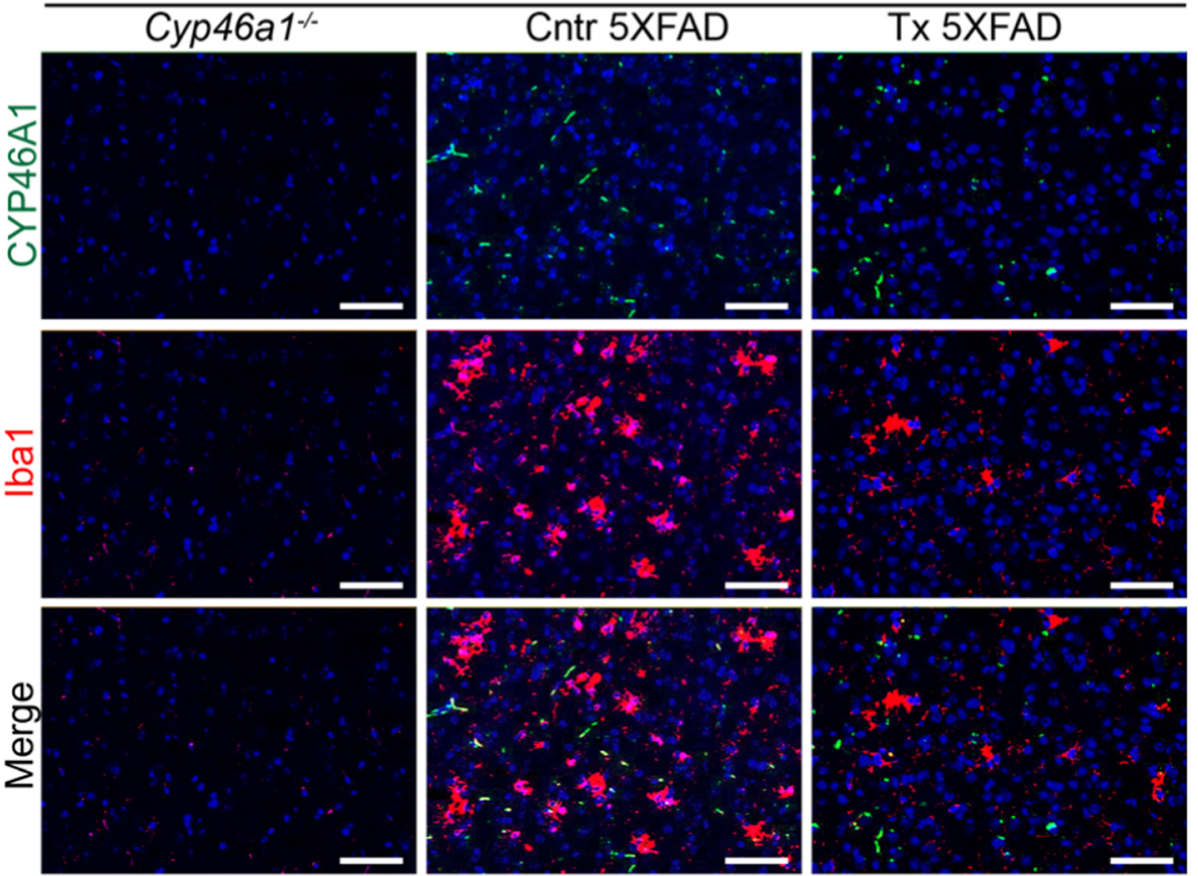

Fig. 4 CYP46A1 co-localizations in the cortex and hippocampus. Representative images ( 3 female and 2 male mice per genotype for antiGFAP stainings and 3 male mice per genotype for anti-lbal stainings) of brain sections double stained with CYP46A1 (in green) and GFAP or Ibal (both in red) as markers for reactive astrocytes (a) and activated microglia (b),

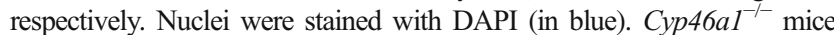
served as a negative control; Cntr, control 5XFAD mice; Tx, EFV-treated 5XFAD mice. Scale bars, $20 \mu \mathrm{m}$ (a) and $100 \mu \mathrm{m}$ (b) ready-release pool (in inhibitory synapses) [51-53] was decreased by $20 \%$. Thus, of the three proteins measured in CYP46A1 transgenic mice and EFV-treated 5XFAD mice, changes in the PSD-95 expression were of the same direction and those of synapsin-1 were in an opposite direction; the expression of synaptophysin remained unchanged in EFV-treated 5XFAD mice.

\section{Discussion}

Collectively, the present work and our previous study [10] led to the two key findings. First, EFV treatment of 5XFAD mice can improve animal performance in behavioral tests regardless of whether the treatment started before or after the appearance $\mathrm{A} \beta$ plaques. Second, the cognitive improvements in EFV- 
Fig. 5 Effect of the 5XFAD genotype on astrocyte and microglia activation in the brain. Representative images ( 3 female and 2 male mice per genotype for anti-GFAP stainigns and 3 male mice per genotype for anti-Iba1 stainings) of brain sections stained with GFAP or Ibal (both in red) as markers for reactive astrocytes (a) and activated microglia (b), respectively. Nuclei were stained with DAPI. B6SJL is a background strain for $5 \mathrm{XFAD}$ mice; Cntr, control 5XFAD mice; Tx, EFV-treated 5XFAD mice.

Scale bars, $20 \mu \mathrm{m}$ a
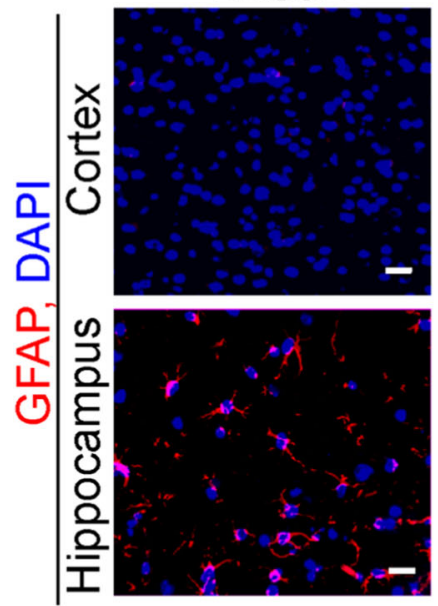

b

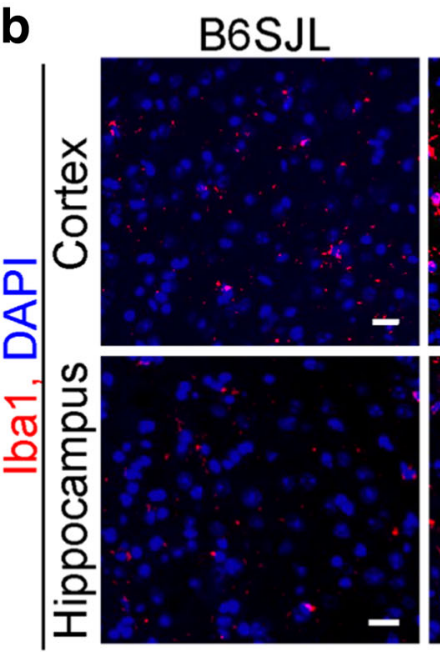

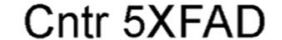

Tx 5XFAD
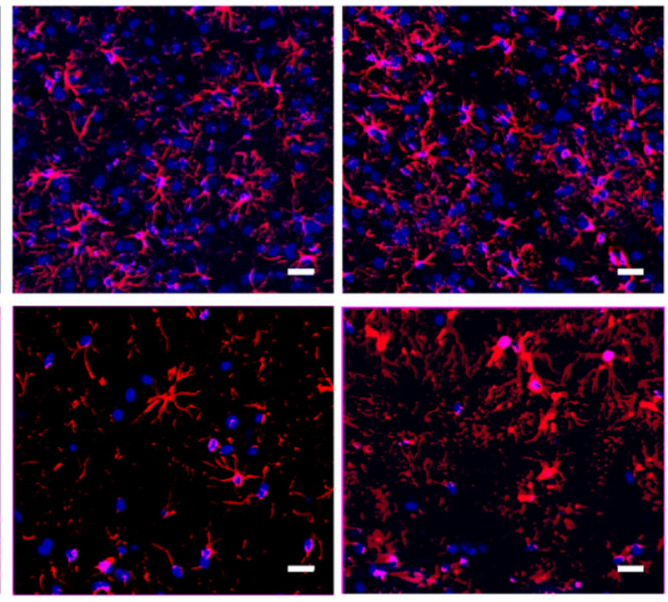

Cntr 5XFAD

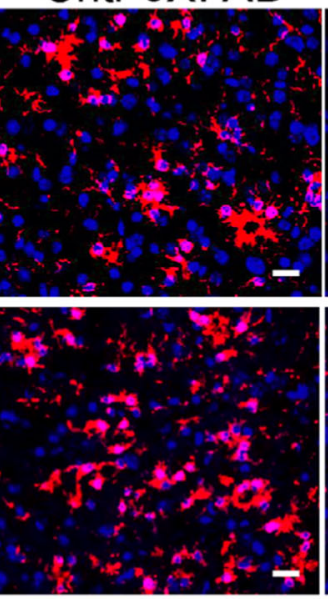

Tx 5XFAD

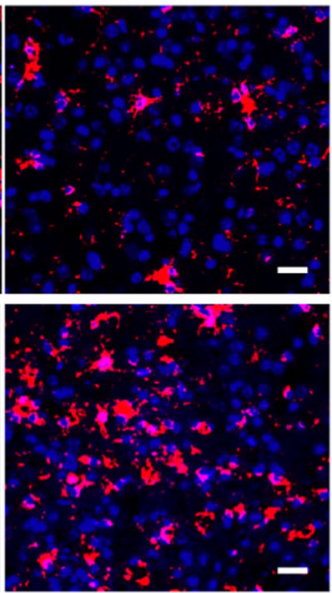

treated 5XFAD mice is not be associated with a decrease in $A \beta$ pathology. This is indicated by unchanged levels of the soluble and insoluble $A \beta 40$ and $A \beta 42$ peptides quantified by ELISA (Fig. 3a) and same levels of the APP/A $\beta$ species stained by $6 \mathrm{E} 10$ (Fig. 3b,c). Yet the number and area of Thioflavin S-positive plaques were slightly decreased (Fig. $3 \mathrm{~d}, \mathrm{e})$. Of importance is that we can suggest the mechanisms for behavioral improvements as a result of EFV treatment (Fig. 8).

EFV treatment activated CYP46A1 and increased cholesterol elimination via metabolism to $24 \mathrm{HC}$ (Fig. 2). However, the brain cholesterol levels were unchanged due to an increase in cholesterol biosynthesis in neurons as evidenced by an increase in the brain levels of lathosterol (Fig. 2). Accordingly CYP46A1 activation led to an increase in neuronal cholesterol turnover. Also, CYP46A1 was detected in some of the reactive astrocytes (Fig. 4a), consistent with a known CYP46A1 expression in some but not all reactive astrocytes in ADaffected human brains $[21,22]$. Thus, CYP46A1 activation by EFV (Fig. 2) and increased reactivity of astrocytes (astrogliosis), as indicated by increased GFAP levels (Fig.
$6 \mathrm{a}, \mathrm{d})$, raise a possibility that astrogliosis is the result of CYP46A1 activation in the enzyme-expressing astrocytes. Animal models of neurological diseases suggest that the effects of astrogliosis are context-specific and could vary from an adaptive beneficial response to a maladaptive deleterious process [54]. Since the astrogliosis in the present work was accompanied by a reduction in microglia activation, as indicated by a decrease in the Ibal levels (Fig. 5b, 6b,d), and behavioral improvements (Fig. 1b-d), it is possible that in EFV-treated 5XFAD mice, astrogliosis plays a beneficial role.

In the brain, microglia accumulate around $\mathrm{A} \beta$ plaques, preferentially dense-core [55-57], and becomes chronically activated as a result of interaction with extracellular fibrillar $\mathrm{A} \beta$ and dying neurons containing intraneuronal $\mathrm{A} \beta[58,59]$. This activated microglia produce neurotoxic cytokines and reactive oxygen species and fails to effectively remove fibrillar forms of $A \beta[60]$. As a result, amyloidoisis is exacerbated along with neuronal damage and neuroinflammation [61]. A recent study showed that reactive astrocytes could switch microglia to a protective phenotype with enhanced phagocytosis, promotion of dendritogenesis, decreased release of 
inflammatory cytokines, and increased secretion of neuroprotective factors [62]. It is conceivable, that a similar mechanism is operative in EFV-treated mice and decreases the Ibal levels (Fig. 6b,d). Alternatively, the mechanism could be different or reciprocal when it is microglia that render astrocytes neuroprotective [63]. A decrease in the Iba1 levels in EFV-treated mice could explain our other findings, namely a small reduction in both brain levels of CYP46A1 (Fig. 6 c,d) and Thioflavin S-positive stains (Fig. 3d,e). The former could be due to a decrease in the oxidative stress, the only factor that was found to upregulate CYP46A1 expression transcriptionally [64], and the latter could due to a partial restoration of a normal microglial function. The Iba1-CYP46A1 link is also supported by an increase in CYP46A1 expression in animal models of traumatic brain injury and hypoxia-ischemia [39, $65,66]$, which are both characterized by an increase in oxidative stress $[67,68]$.

Individually or collectively, increases in $24 \mathrm{HC}$, neuronal cholesterol turnover, and astrocyte reactivity as well as decreases in microglia activation and dense-core amyloid plaques (Fig. 8) could affect the levels of synaptic proteins (Fig. 7). 24HC is a positive allosteric modulator of NMDAR $[11,12,69,70]$, whose activation initiates multiple memoryrelated signaling cascades, which ultimately lead to changes in the levels of synaptic proteins [71-73]. 24HC is a ligand for LXRs [74], transcription factors, whose activation by a synthetic ligand was shown to alter the levels of several synaptic proteins and promoted neurite outgrowth [16]. CYP46A1 activity controls cholesterol turnover and hence isoprenoid production and availability for prenylation of proteins involved in long-term potentiation [75-77]. The contribution of reactive astrocytes and activated microglia to changes in the levels of synaptic proteins could be via the participation in synaptic plasticity, maintenance and remodeling [78, 79]. Finally, in the brain, dense core amyloid plaques are mostly located in the vicinity of synapses and were shown to cause synapse loss and hence a decrease in synaptic proteins because of the $A \beta$ toxicity in the halo of the plaques [80-83].

EFV treatment of 5XFAD mice increased the brain levels of Munc13-1 and PSD-95, while decreasing the expression of synapsin-1. Munc13-1, a presynaptic component, is more important for glutamate rather than GABA release because its function for the latter is redundant [44, 45, 84]. PSD-95 is a scaffold protein for postsynaptic components, including NMDAR [46]. Synapsin-1 modulates neurotransmitter release: in excitatory synapses, synapsin-1 attenuates neurotransmitter release by restraining synaptic vesicles in the reserve (inactive) pool; in inhibitory (GABAerigic) synapses, synapsin-1 facilitates neurotransmitter release by recruiting synaptic vesicles in the ready-release pool [51, 52]. Staring from 6 months of age, 5XFAD mice have synaptic loss (as indicated by a decrease in the PSD-95 $[32,85]$ ) as well as decreases in glutamatergic transmission and synaptic plasticity [86-88]. Accordingly, changes in Munc13-1, PSD-95, and synapsin-1 found in this work suggest that the synaptic function could be improved as a result of EFV treatment. At the same time, EFV treatment did not appear to change the levels of gephyrin, the main scaffold protein for inhibitory
Fig. 6 EFV effect on total brain levels of GFAP, Iba1, and CYP46A1. (a-c) Representative Western blots of brain homogenates from control (Cntr, $n=4)$ and EFV-treated (Tx, $n=5)$ 5XFAD male mice. Each lane, except those with molecular weight markers $(\mathbf{a}, \mathbf{b})$ and purified recombinant CYP46A1 (c), represents a sample from individual animal. (d) Quantification of the relative protein expression after normalization to the $\beta$-actin signal. The results are presented as means $\pm \mathrm{SD}$ of measurements in individual mice; $* P \leq 0.05$ and $* * * P \leq 0.001$ by a two-tailed, unpaired Student's t test
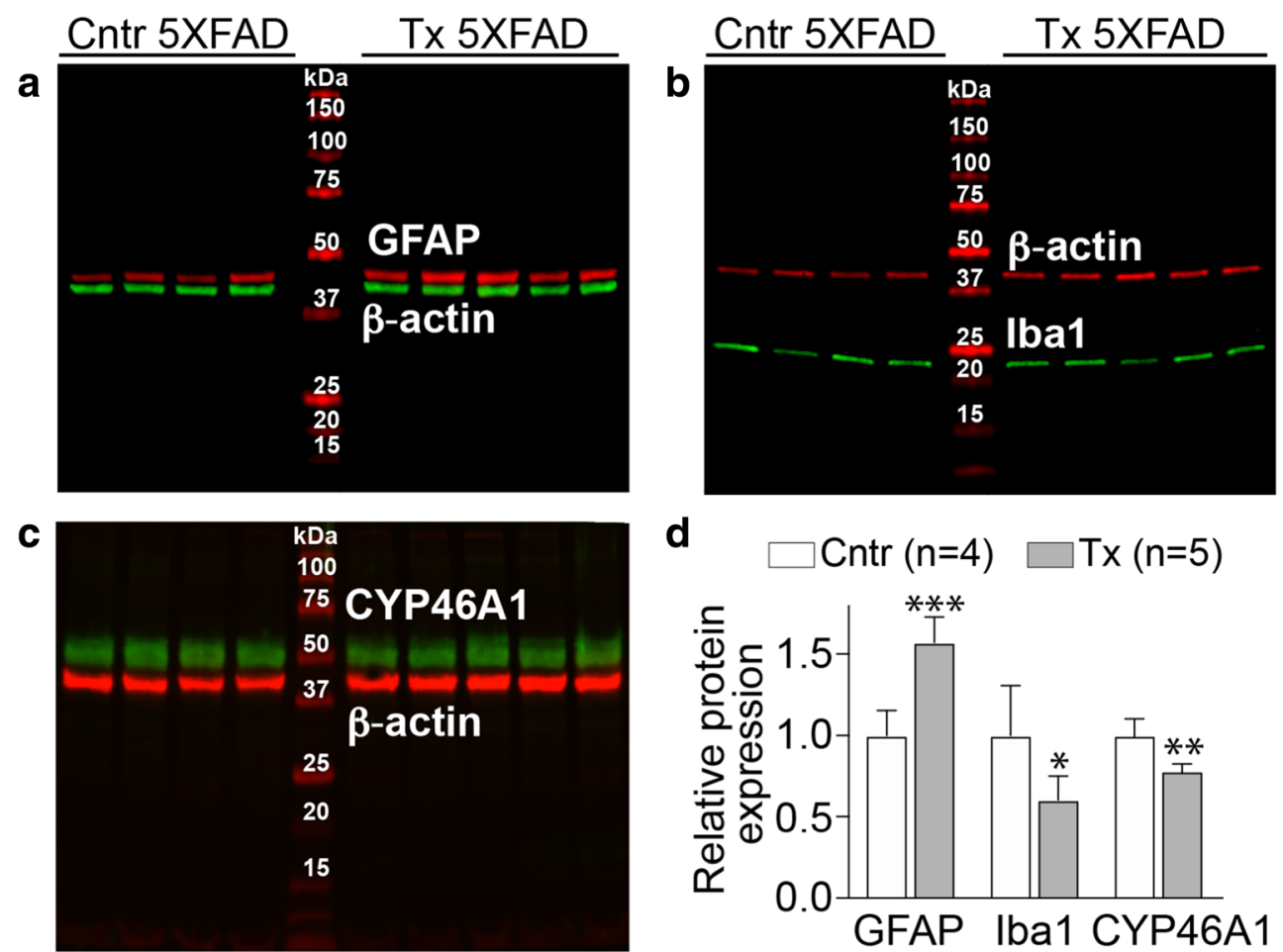


\section{a Excitatory Synapse (Glutamatergic)}
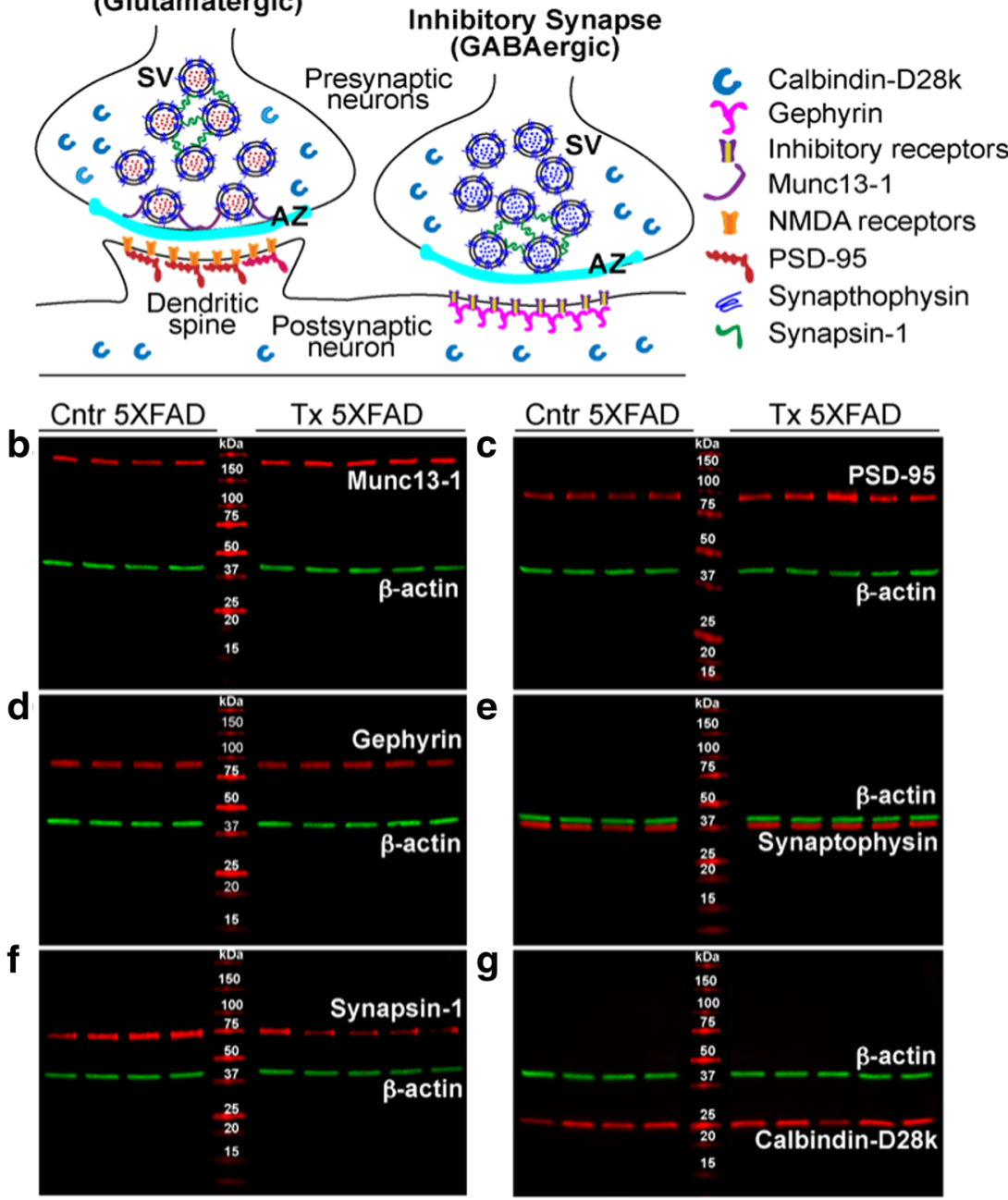

E
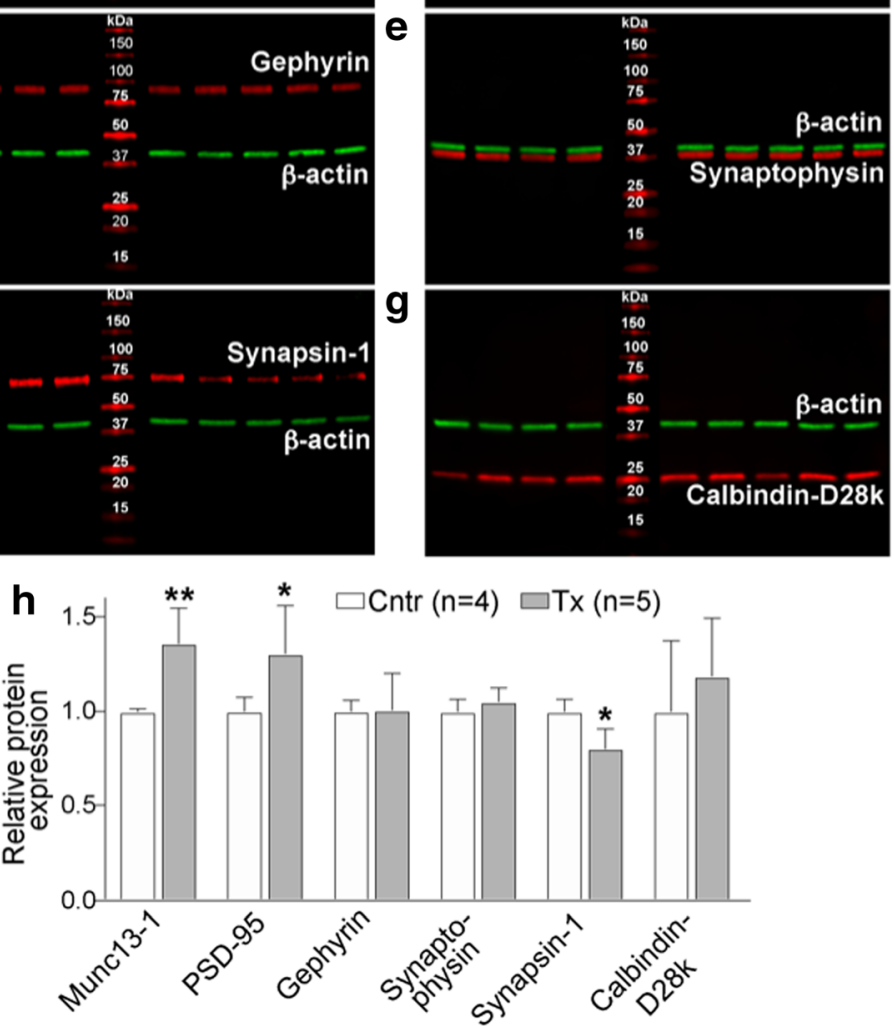

Fig. 7 EFV effect on the levels of synaptic proteins. (a) Location of the studied proteins in excitatory (glutamatergic) and inhibitory (GABAergic) axodendritic synapses. AZ, active zone (cyan), a specialized part of presynaptic membranes containing sites for vesicle exocytosis; SV, synaptic vesicles filled with a neurotransmitter (glutamate or GABA, red and blue circles, respectively). Munc13-1 is a presynaptic $\mathrm{AZ}$ component essential for fusion competence of $\mathrm{SV}$ in glutamatergic but not GABAergic synapses. PSD-95 is a major postsynaptic scaffold protein that clusters NMDA receptors. Gephyrin is the major postsynaptic scaffold protein that anchors inhibitory neurotransmitter receptors to the postsynaptic cytoskeleton. Synaptophysin is the most abundant transmembrane protein in SV that regulates vesicle retrieval and exocytosis.
Synapsin-1 is the protein that connects SV and retains them in the reserve pool in excitatory synapses and in the ready releasable pool in inhibitory synapses. Calbindin-D28k is a neuronal $\mathrm{Ca}^{2+}$-buffering protein expressed in the nucleus and throughout the cytoplasm of many neurons. (b-g) Representative Western blots of brain homogenates from control (Cntr, $\mathrm{n}=4)$ and EFV-treated (Tx, n= 5) 5XFAD male mice. Each lane, except those with molecular weight markers, represents a sample from individual animal. (h) Quantification of the relative protein expression after normalization to the $\beta$-actin signal. The results are presented as means $\pm \mathrm{SD}$ of measurements in individual mice; $* P \leq 0.05$ and $* * P \leq 0.01$ by a twotailed, unpaired Student's $t$ test 
postsynaptic receptors [47], and synaptophysin, a marker for synaptic vesicles [48]. These data could indicate that inhibitory (GABAergic) synapses were not markedly affected, and the total amount of synaptic vesicles was unchanged in EFVtreated 5XFAD mice. Unchanged levels of calbindin-D28k, a neuronal protein $[49,50]$, suggest a lack of appreciable neuronal loss. i.e., EFV neurotoxicity.

Putative improvement in synaptic function in EFV-treated mice may lead in turn to improvements in the behavioral tests (MWM and contextual fear conditioning) (Fig. 1b-d), which both depend on hippocampal NMDAR [89, 90]. There were no significant improvements in the Y-maze (spontaneous alternations) and cued fear conditioning tests (Fig. 1a,e), which highly depend on the brain areas other than the hippocampus $[91,92]$. These results suggest that the main target area for EFV treatment in 5XFAD mice is the hippocampus, also one of the most affected brain areas in $\mathrm{AD}$ [93].

Behavioral improvements in EFV-treated mice were not accompanied by changes in the amyloid species detected by ELISA and 6E10 (Fig. 3a,b). This outcome is consistent with clinical studies showing a lack of strong correlation between $A \beta$ deposition and cognitive deficits as well as observations that patients with mild cognitive impairment and asymptomatic healthy controls may have significant $A \beta$ accumulation $[33,34]$. Thus, in the studied treatment paradigm, EFV-treated 5XFAD mice could represent an amyloid-independent model of behavioral and other improvements despite a slight decrease in the dense core amyloid plaque load. Only several amyloidindependent models are known: mutant APP transgenic mice injected with the gene for brain-derived neurotropic factor [94]; 5XFAD mice with elimination of $80 \%$ of microglia [42]; and APP-presenelin1 transgenic mice with inhibited phosphodiesterase 4 [95].

As in any drug treatment study, there is always a possibility that the observed behavioral improvements in 5XFAD mice are due to off-target EFV effects that are not related to CYP46A1 activation. We minimized this possibility by using a very small EFV dose in our treatments, and we are also testing EFV on Cyp46a1 ${ }^{-/} 5 \mathrm{XFAD}$ mice that we generated.

EFV-administration to 5XFAD mice generated the data that served as a basis for a proof-of-concept clinical research study of EFV in patients with AD (ClinicalTrials.gov, NCT03706885). The primary endpoints of this clinical trial are to ascertain whether the two studied EFV doses (50 and $200 \mathrm{mg} /$ day): 1) engage CYP46A1 and affect brain cholesterol metabolism; 2) increase plasma $24 \mathrm{HC}$ concentrations, and 3) are safe and tolerable in the geriatric population. Neurocognitive assessments and the measurements of $A \beta$, total tau, and phosphotau in the patient cerebrospinal fluid will be conducted as well but are not among the trial endpoints. The new and important insight from the present work is that EFV treatment could lead to behavioral improvements but do not have an effect on the $\mathrm{A} \beta$ content in the patient cerebrospinal fluid.

In summary, EFV treatment of 5XFAD mice from 3 to 9 months of age did not significantly affect the levels of the $A \beta$ peptides but improved animal performance in hippocampus-dependent MWM and contextual fear conditioning tests. Behavioral improvements were accompanied by increases in brain content of $24 \mathrm{HC}$, neuronal cholesterol turnover, and specific presynaptic and postsynaptic proteins. Increased astrocyte reactivity and decreased microglia activation were observed as well. Thus, CYP46A1 activation by
Fig. 8 A summary of changes in EFV-treated 5XFAD mice. See Discussion for explanation. Biological processes are in bold; supporting experimental data are in regular font. Black arrows indicate the links with experimental support; gray arrows are the suggested links based on literature data. $\uparrow, \downarrow$, and $\leftrightarrow$ indicate increase, decrease, and no change, respectively. ROS, reactive oxygen species

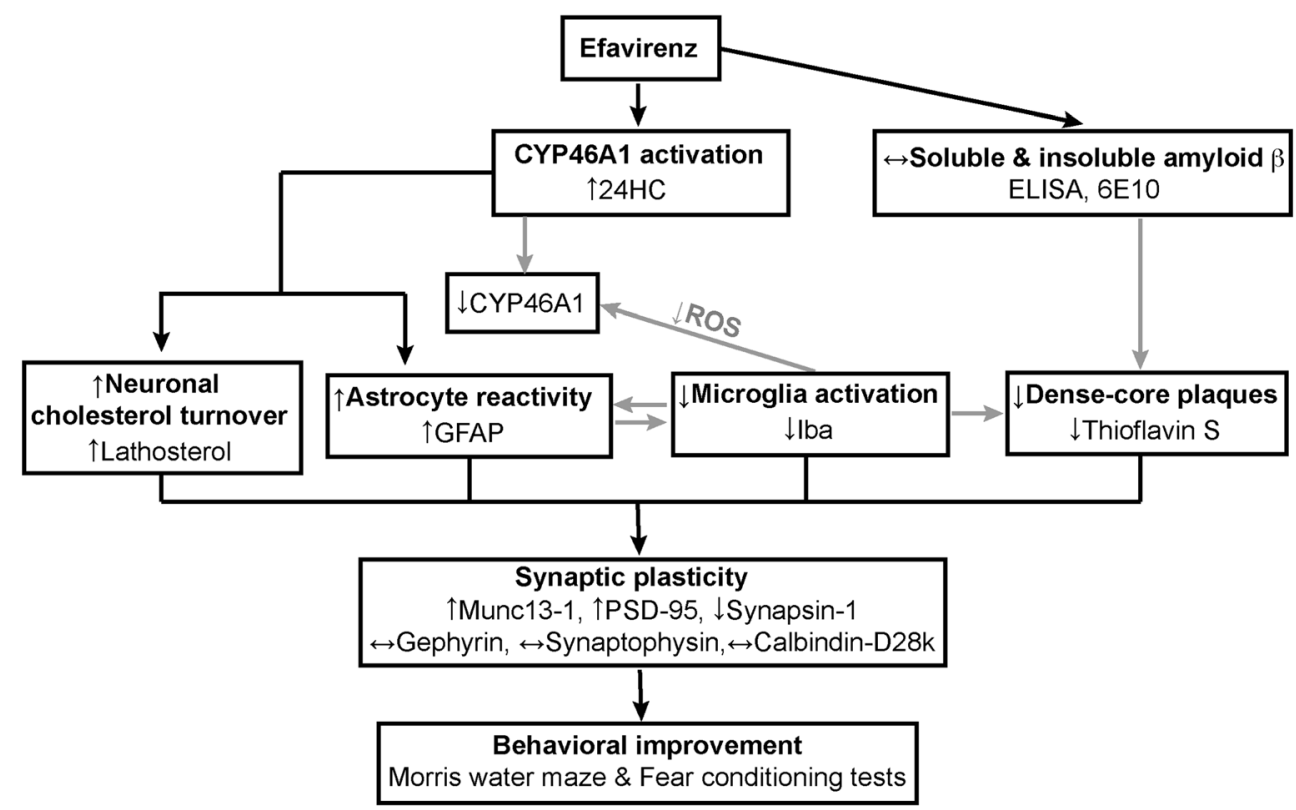


EFV after $A \beta$ deposition has effects on multiple brain processes related to $\mathrm{AD}$.

Acknowledgments This work was supported in part in by National Institute of General Medical Sciences grant GM062882 (IAP). The authors thank the Visual Sciences Research Center Core Facilities (supported by National Institutes of Health Grant P30 EY11373) for assistance with mouse breeding (Heather Butler and Kathryn Franke), animal genotyping (John Denker), tissue sectioning (Catherine Doller), and microscopy (Anthony Gardella). We are also grateful to Dr. Hiroyuki Arakawa for behavioral testing.

Author Contributions IAP conceived and designed the study; ML, NM, JM, YL, and EM performed the experiments; IP, NM, AMP, and ML analyzed the data; IAP and AMP wrote the paper; IAP acquired funding.

\section{Compliance with Ethical Standards}

Conflict of Interest The authors declare no conflict of interest.

\section{References}

1. Blesa R, Toriyama K, Ueda K, et al (2018). Strategies for Continued Successful Treatment in Patients with Alzheimer's Disease: An Overview of Switching Between Pharmacological Agents. Curr Alzheimer Res 15: 964-974

2. Lutjohann D, Breuer O, Ahlborg G, et al (1996). Cholesterol homeostasis in human brain: evidence for an age-dependent flux of 24S-hydroxycholesterol from the brain into the circulation. Proc Natl Acad Sci U S A 93: 9799-9804

3. Lund EG, Guileyardo JM, Russell DW (1999). cDNA cloning of cholesterol 24-hydroxylase, a mediator of cholesterol homeostasis in the brain. Proc Natl Acad Sci U S A 96: 7238-7243

4. Ramirez DM, Andersson S, Russell DW (2008). Neuronal expression and subcellular localization of cholesterol 24-hydroxylase in the mouse brain. J Comp Neurol 507: 1676-1693

5. Meaney S, Bodin K, Diczfalusy U, et al (2002). On the rate of translocation in vitro and kinetics in vivo of the major oxysterols in human circulation: critical importance of the position of the oxygen function. J Lipid Res 43: 2130-2135

6. Dietschy JM (2009). Central nervous system: cholesterol turnover, brain development and neurodegeneration. Biol Chem 390: 287293

7. Lund EG, Xie C, Kotti T, et al (2003). Knockout of the cholesterol 24-hydroxylase gene in mice reveals a brain-specific mechanism of cholesterol turnover. J Biol Chem 278: 22980-22988

8. Pfrieger FW, Ungerer N (2011). Cholesterol metabolism in neurons and astrocytes. Prog Lipid Res 50: 357-371

9. Mast N, Li Y, Linger M, et al (2014). Pharmacologic stimulation of cytochrome P450 46A1 and cerebral cholesterol turnover in mice. J Biol Chem 289: 3529-3538

10. Mast N, Saadane A, Valencia-Olvera A, et al (2017). Cholesterolmetabolizing enzyme cytochrome $\mathrm{P} 450 \mathrm{46 \textrm {A } 1}$ as a pharmacologic target for Alzheimer's disease. Neuropharmacology 123: 465-476

11. Paul SM, Doherty JJ, Robichaud AJ, et al (2013). The major brain cholesterol metabolite 24(S)-hydroxycholesterol is a potent allosteric modulator of $\mathrm{N}$-methyl-D-aspartate receptors. J Neurosci 33: 17290-17300

12. Sun MY, Izumi Y, Benz A, et al (2016). Endogenous 24Shydroxycholesterol modulates NMDAR-mediated function in hippocampal slices. J Neurophysiol 115: 1263-1272
13. Kalaany NY, Mangelsdorf DJ (2006). LXRS and FXR: the yin and yang of cholesterol and fat metabolism. Annu Rev Physiol 68: 159191

14. Calkin AC, Tontonoz P (2012). Transcriptional integration of metabolism by the nuclear sterol-activated receptors LXR and FXR. Nat Rev Mol Cell Biol 13: 213-224

15. Glass CK, Ogawa S (2006). Combinatorial roles of nuclear receptors in inflammation and immunity. Nat Rev Immunol 6: 44-55

16. Chen J, Zacharek A, Cui X, et al (2010). Treatment of stroke with a synthetic liver X receptor agonist, TO901317, promotes synaptic plasticity and axonal regeneration in mice. J Cereb Blood Flow Metab 30: 102-109

17. Peng Z, Deng B, Jia J, et al (2018). Liver X receptor beta in the hippocampus: A potential novel target for the treatment of major depressive disorder? Neuropharmacology 135: 514-528

18. Lutjohann D, Papassotiropoulos A, Bjorkhem I, et al (2000). Plasma 24S-hydroxycholesterol (cerebrosterol) is increased in Alzheimer and vascular demented patients. J Lipid Res 41: 195198

19. Bretillon L, Siden A, Wahlund LO, et al (2000). Plasma levels of 24S-hydroxycholesterol in patients with neurological diseases. Neurosci Lett 293: 87-90

20. Kolsch H, Heun R, Kerksiek A, et al (2004). Altered levels of plasma 24S- and 27-hydroxycholesterol in demented patients. Neurosci Lett 368: 303-308

21. Bogdanovic N, Bretillon L, Lund EG, et al (2001). On the turnover of brain cholesterol in patients with Alzheimer's disease. Abnormal induction of the cholesterol-catabolic enzyme CYP46 in glial cells. Neurosci Lett 314: 45-48

22. Brown J, 3rd, Theisler C, Silberman S, et al (2004). Differential expression of cholesterol hydroxylases in Alzheimer's disease. $\mathrm{J}$ Biol Chem 279: 34674-34681

23. Tian G, Kong Q, Lai L, et al (2010). Increased expression of cholesterol 24S-hydroxylase results in disruption of glial glutamate transporter EAAT2 association with lipid rafts: a potential role in Alzheimer's disease. J Neurochem 113: 978-989

24. Russell DW, Halford RW, Ramirez DM, et al (2009). Cholesterol 24-hydroxylase: an enzyme of cholesterol turnover in the brain. Annu Rev Biochem 78: 1017-1040

25. Hudry E, Van Dam D, Kulik W, et al (2010). Adeno-associated virus gene therapy with cholesterol 24-hydroxylase reduces the amyloid pathology before or after the onset of amyloid plaques in mouse models of Alzheimer's disease. Mol Ther 18: 44-53

26. Bryleva EY, Rogers MA, Chang CC, et al (2010). ACAT1 gene ablation increases 24(S)-hydroxycholesterol content in the brain and ameliorates amyloid pathology in mice with AD. Proc Natl Acad Sci U S A 107: 3081-3086

27. Burlot MA, Braudeau J, Michaelsen-Preusse K, et al (2015). Cholesterol 24-hydroxylase defect is implicated in memory impairments associated with Alzheimer-like Tau pathology. Hum Mol Genet 24: 5965-5976

28. Djelti F, Braudeau J, Hudry E, et al (2015). CYP46A1 inhibition, brain cholesterol accumulation and neurodegeneration pave the way for Alzheimer's disease. Brain 138: 2383-2398

29. Ayciriex S, Djelti F, Alves S, et al (2017). Neuronal Cholesterol Accumulation Induced by Cyp46a1 Down-Regulation in Mouse Hippocampus Disrupts Brain Lipid Homeostasis. Front Mol Neurosci 10: 211

30. Halford RW, Russell DW (2009). Reduction of cholesterol synthesis in the mouse brain does not affect amyloid formation in Alzheimer's disease, but does extend lifespan. Proc Natl Acad Sci U S A 106: 3502-3506

31. Anderson KW, Mast N, Hudgens JW, et al (2016). Mapping of the Allosteric Site in Cholesterol Hydroxylase CYP46A1 for Efavirenz, a Drug That Stimulates Enzyme Activity. J Biol Chem 291: $11876-11886$ 
32. Oakley H, Cole SL, Logan S, et al (2006). Intraneuronal betaamyloid aggregates, neurodegeneration, and neuron loss in transgenic mice with five familial Alzheimer's disease mutations: potential factors in amyloid plaque formation. J Neurosci 26: 1012910140

33. Hyman BT (2011). Amyloid-dependent and amyloid-independent stages of Alzheimer disease. Arch Neurol 68: 1062-1064

34. Karran E, Mercken M, De Strooper B (2011). The amyloid cascade hypothesis for Alzheimer's disease: an appraisal for the development of therapeutics. Nat Rev Drug Discov 10: 698-712

35. Mast N, Reem R, Bederman I, et al (2011). Cholestenoic Acid is an important elimination product of cholesterol in the retina: comparison of retinal cholesterol metabolism with that in the brain. Invest Ophthalmol Vis Sci 52: 594-603

36. Heo GY, Liao WL, Turko IV, et al (2012). Features of the retinal environment which affect the activities and product profile of cholesterol-metabolizing cytochromes P450 CYP27A1 and CYP11A1. Arch Biochem Biophys 518: 119-126

37. Schmidt SD, Jiang Y, Nixon RA, et al (2005). Tissue processing prior to protein analysis and amyloid-beta quantitation. Methods Mol Biol 299: 267-278

38. Dickson DW (1997). The pathogenesis of senile plaques. J Neuropathol Exp Neurol 56: 321-339

39. Cartagena CM, Ahmed F, Burns MP, et al (2008). Cortical injury increases cholesterol 24S hydroxylase (Cyp46) levels in the rat brain. J Neurotrauma 25: 1087-1098

40. Lewis GP, Fisher SK (2003). Up-regulation of glial fibrillary acidic protein in response to retinal injury: its potential role in glial remodeling and a comparison to vimentin expression. Int Rev Cytol 230: 263-290

41. Santos AM, Calvente R, Tassi M, et al (2008). Embryonic and postnatal development of microglial cells in the mouse retina. $\mathrm{J}$ Comp Neurol 506: 224-239

42. Spangenberg EE, Lee RJ, Najafi AR, et al (2016). Eliminating microglia in Alzheimer's mice prevents neuronal loss without modulating amyloid-beta pathology. Brain 139: 1265-1281

43. Maioli S, Bavner A, Ali Z, et al (2013). Is it possible to improve memory function by upregulation of the cholesterol 24Shydroxylase (CYP46A1) in the brain? PLoS One 8: e68534-e68534

44. Augustin I, Rosenmund C, Sudhof TC, et al (1999). Munc13-1 is essential for fusion competence of glutamatergic synaptic vesicles. Nature 400: 457-461

45. Betz A, Thakur P, Junge HJ, et al (2001). Functional interaction of the active zone proteins Munc13-1 and RIM1 in synaptic vesicle priming. Neuron 30: 183-196

46. Kornau HC, Schenker LT, Kennedy MB, et al (1995). Domain interaction between NMDA receptor subunits and the postsynaptic density protein PSD-95. Science 269: 1737-1740

47. Choii G, Ko J (2015). Gephyrin: a central GABAergic synapse organizer. Exp Mol Med 47: e158

48. Kwon SE, Chapman ER (2011). Synaptophysin regulates the kinetics of synaptic vesicle endocytosis in central neurons. Neuron 70: $847-854$

49. Kook SY, Jeong H, Kang MJ, et al (2014). Crucial role of calbindinD28k in the pathogenesis of Alzheimer's disease mouse model. Cell Death Differ 21: 1575-1587

50. Pickel VM, Heras A (1996). Ultrastructural localization of calbindin-D28k and GABA in the matrix compartment of the rat caudate-putamen nuclei. Neuroscience 71: 167-178

51. Denker A, Bethani I, Krohnert K, et al (2011). A small pool of vesicles maintains synaptic activity in vivo. Proc Natl Acad Sci U S A 108: 17177-17182

52. Gitler D, Takagishi Y, Feng J, et al (2004). Different presynaptic roles of synapsins at excitatory and inhibitory synapses. J Neurosci 24: $11368-11380$
53. Shupliakov O, Haucke V, Pechstein A (2011). How synapsin I may cluster synaptic vesicles. Semin Cell Dev Biol 22: 393-399

54. Pekny M, Pekna M, Messing A, et al (2016). Astrocytes: a central element in neurological diseases. Acta Neuropathol 131: 323-345

55. Mackenzie IR, Hao C, Munoz DG (1995). Role of microglia in senile plaque formation. Neurobiol Aging 16: 797-804

56. Akiyama H, Mori H, Saido T, et al (1999). Occurrence of the diffuse amyloid beta-protein (Abeta) deposits with numerous Abetacontaining glial cells in the cerebral cortex of patients with Alzheimer's disease. Glia 25: 324-331

57. Nagele RG, Wegiel J, Venkataraman V, et al (2004). Contribution of glial cells to the development of amyloid plaques in Alzheimer's disease. Neurobiol Aging 25: 663-674

58. Ferrera D, Mazzaro N, Canale C, et al (2014). Resting microglia react to Abeta42 fibrils but do not detect oligomers or oligomerinduced neuronal damage. Neurobiol Aging 35: 2444-2457

59. Hanzel CE, Pichet-Binette A, Pimentel LS, et al (2014). Neuronal driven pre-plaque inflammation in a transgenic rat model of Alzheimer's disease. Neurobiol Aging 35: 2249-2262

60. Malm TM, Jay TR, Landreth GE (2015). The evolving biology of microglia in Alzheimer's disease. Neurotherapeutics 12: 81-93

61. Piirainen S, Youssef A, Song C, et al (2017). Psychosocial stress on neuroinflammation and cognitive dysfunctions in Alzheimer's disease: the emerging role for microglia? Neurosci Biobehav Rev 77: $148-164$

62. Xing C, Li W, Deng W, et al (2018). A potential gliovascular mechanism for microglial activation: differential phenotypic switching of microglia by endothelium versus astrocytes. J Neuroinflammation 15: 143

63. Shinozaki Y, Shibata K, Yoshida K, et al (2017). Transformation of Astrocytes to a Neuroprotective Phenotype by Microglia via P2Y1 Receptor Downregulation. Cell Rep 19: 1151-1164

64. Ohyama Y, Meaney S, Heverin M, et al (2006). Studies on the transcriptional regulation of cholesterol 24-hydroxylase (CYP46A1): marked insensitivity toward different regulatory axes. J Biol Chem 281: 3810-3820

65. Lu F, Zhu J, Guo S, et al (2018). Upregulation of cholesterol 24hydroxylase following hypoxia-ischemia in neonatal mouse brain. Pediatr Res 83: 1218-1227

66. Smiljanic K, Lavrnja I, Mladenovic Djordjevic A, et al (2010). Brain injury induces cholesterol 24-hydroxylase (Cyp46) expression in glial cells in a time-dependent manner. Histochem Cell Biol 134: $159-169$

67. Khatri N, Thankur M, Pareek V, et al (2018). Oxidative stress: Major threat in traumatic brain injury. CNS Neurol Disord Drug Targets 17: 689-695

68. Thornton C, Baburamani AA, Kichev A, et al (2017). Oxidative stress and endoplasmic reticulum (ER) stress in the development of neonatal hypoxic-ischaemic brain injury. Biochem Soc Trans 45: $1067-1076$

69. Linsenbardt AJ, Taylor A, Emnett CM, et al (2014). Different oxysterols have opposing actions at N-methyl-D-aspartate receptors. Neuropharmacology 85: 232-242

70. Sun MY, Linsenbardt AJ, Emnett CM, et al (2016). 24(S)Hydroxycholesterol as a modulator of neuronal signaling and survival. Neuroscientist 22: 132-144

71. Abraham WC, Williams JM (2008). LTP maintenance and its protein synthesis-dependence. Neurobiol Learn Mem 89: 260-268

72. Hoeffer CA, Klann E 2009 NMDA Receptors and Translational Control. In Biology of the NMDA Receptor. A. M. Van Dongen, editor. CRC Press/Taylor \& Francis. Taylor \& Francis Group, LLC., Boca Raton (FL), 103-121

73. Bramham CR (2008). Local protein synthesis, actin dynamics, and LTP consolidation. Curr Opin Neurobiol 18: 524-531 
74. Janowski BA, Willy PJ, Devi TR, et al (1996). An oxysterol signalling pathway mediated by the nuclear receptor LXR alpha. Nature 383: 728-731

75. Kotti TJ, Ramirez DM, Pfeiffer BE, et al (2006). Brain cholesterol turnover required for geranylgeraniol production and learning in mice. Proc Natl Acad Sci U S A 103: 3869-3874

76. Kotti T, Head DD, McKenna CE, et al (2008). Biphasic requirement for geranylgeraniol in hippocampal long-term potentiation. Proc Natl Acad Sci U S A 105: 11394-11399

77. Moutinho M, Nunes MJ, Gomes AQ, et al (2015). Cholesterol 24SHydroxylase Overexpression Inhibits the Liver X Receptor (LXR) Pathway by Activating Small Guanosine Triphosphate-Binding Proteins (sGTPases) in Neuronal Cells. Mol Neurobiol 51: 14891503

78. Allen NJ, Eroglu C (2017). Cell Biology of Astrocyte-Synapse Interactions. Neuron 96: 697-708

79. Wu Y, Dissing-Olesen L, MacVicar BA, et al (2015). Microglia: Dynamic Mediators of Synapse Development and Plasticity. Trends Immunol 36: 605-613

80. Koffie RM, Meyer-Luehmann M, Hashimoto T, et al (2009). Oligomeric amyloid beta associates with postsynaptic densities and correlates with excitatory synapse loss near senile plaques. Proc Natl Acad Sci USA 106: 4012-4017

81. Spires-Jones TL, Meyer-Luehmann M, Osetek JD, et al (2007). Impaired spine stability underlies plaque-related spine loss in an Alzheimer's disease mouse model. Am J Pathol 171: 1304-1311

82. Ovsepian SV, Blazquez-Llorca L, Freitag SV, et al (2017). Ambient Glutamate Promotes Paroxysmal Hyperactivity in Cortical Pyramidal Neurons at Amyloid Plaques via Presynaptic mGluR1 Receptors. Cereb Cortex 27: 4733-4749

83. Ovsepian SV, O'Leary VB, Zaborszky L, et al (2018). Amyloid Plaques of Alzheimer's Disease as Hotspots of Glutamatergic Activity. Neuroscientist: in press

84. Varoqueaux F, Sigler A, Rhee JS, et al (2002). Total arrest of spontaneous and evoked synaptic transmission but normal synaptogenesis in the absence of Munc13-mediated vesicle priming. Proc Natl Acad Sci U S A 99: 9037-9042

85. Shao CY, Mirra SS, Sait HB, et al (2011). Postsynaptic degeneration as revealed by PSD-95 reduction occurs after advanced Abeta and tau pathology in transgenic mouse models of Alzheimer's disease. Acta Neuropathol 122: 285-292
86. Crouzin N, Baranger K, Cavalier M, et al (2013). Area-specific alterations of synaptic plasticity in the 5XFAD mouse model of Alzheimer's disease: dissociation between somatosensory cortex and hippocampus. PLoS One 8: e74667

87. Kimura R, Ohno M (2009). Impairments in remote memory stabilization precede hippocampal synaptic and cognitive failures in 5XFAD Alzheimer mouse model. Neurobiology of disease 33: 229-235

88. Ovsepian SV, O'Leary VB, Zaborszky L, et al (2018). Synaptic vesicle cycle and amyloid beta: Biting the hand that feeds. Alzheimers Dement 14: 502-513

89. Vorhees CV, Williams MT (2006). Morris water maze: procedures for assessing spatial and related forms of learning and memory. Nat Protoc 1: 848-858

90. Young SL, Bohenek DL, Fanselow MS (1994). NMDA processes mediate anterograde amnesia of contextual fear conditioning induced by hippocampal damage: immunization against amnesia by context preexposure. Behav Neurosci 108: 19-29

91. Sarnyai Z, Sibille EL, Pavlides C, et al (2000). Impaired hippocampal-dependent learning and functional abnormalities in the hippocampus in mice lacking serotonin(1A) receptors. Proc Natl Acad Sci U S A 97: 14731-14736

92. Anagnostaras SG, Wood SC, Shuman T, et al (2010). Automated assessment of pavlovian conditioned freezing and shock reactivity in mice using the video freeze system. Front Behav Neurosci 4: 158

93. Maruszak A, Thuret S (2014). Why looking at the whole hippocampus is not enough-a critical role for anteroposterior axis, subfield and activation analyses to enhance predictive value of hippocampal changes for Alzheimer's disease diagnosis. Front Cell Neurosci 8: 95-95

94. Nagahara AH, Merrill DA, Coppola G, et al (2009). Neuroprotective effects of brain-derived neurotrophic factor in rodent and primate models of Alzheimer's disease. Nat Med 15:331337

95. Gong B, Vitolo OV, Trinchese F, et al (2004). Persistent improvement in synaptic and cognitive functions in an Alzheimer mouse model after rolipram treatment. J Clin Invest 114: 1624-1634

Publisher's Note Springer Nature remains neutral with regard to jurisdictional claims in published maps and institutional affiliations. 